\title{
Turbulent flow as a cause for underestimating coronary flow reserve measured by Doppler guide wire
}

\author{
Markus Ferrari*1, Gerald S Werner ${ }^{2}$, Philipp Bahrmann ${ }^{1}$, Barbara M Richartz ${ }^{1}$ \\ and Hans R Figulla ${ }^{1}$
}

\author{
Address: ${ }^{1}$ Clinic of Internal Medicine I, Friedrich-Schiller-University, Jena, Germany and ${ }^{2}$ Clinic of Internal Medicine, City Clinical Center \\ Darmstadt, Germany \\ Email: Markus Ferrari* - markus.ferrari@med.uni-jena.de; Gerald S Werner - Gerald.Werner@med.uni-jena.de; \\ Philipp Bahrmann - philipp.bahrmann@med.uni-jena.de; Barbara M Richartz - info.richartz@kliche.de; Hans R Figulla - hans.figulla@med.uni- \\ jena.de \\ * Corresponding author
}

Published: 22 March 2006

Cardiovascular Ultrasound2006, 4:14 doi:10.1/86/1476-7|20-4-14
Received: 12 February 2006

Accepted: 22 March 2006

This article is available from: http://www.cardiovascularultrasound.com/content/4/I/I4

(c) 2006Ferrari et al; licensee BioMed Central Ltd.

This is an Open Access article distributed under the terms of the Creative Commons Attribution License (http://creativecommons.org/licenses/by/2.0), which permits unrestricted use, distribution, and reproduction in any medium, provided the original work is properly cited.

\begin{abstract}
Background: Doppler-tipped coronary guide-wires (FW) are well-established tools in interventional cardiology to quantitatively analyze coronary blood flow. Doppler wires are used to measure the coronary flow velocity reserve (CFVR). The CFVR remains reduced in some patients despite anatomically successful coronary angioplasty. It was the aim of our study to test the influence of changes in flow profile on the validity of intra-coronary Doppler flow velocity measurements in vitro. It is still unclear whether turbulent flow in coronary arteries is of importance for physiologic studies in vivo.

Methods: We perfused glass pipes of defined inner diameters $(1.5-5.5 \mathrm{~mm})$ with heparinized blood in a pulsatile flow model. Laminar and turbulent flow profiles were achieved by varying the flow velocity. The average peak velocity (APV) was recorded using 0.014 inch FW. Flow velocity measurements were also performed in 75 patients during coronary angiography. Coronary hyperemia was induced by intracoronary injection of adenosine. The APV maximum was taken for further analysis. The mean luminal diameter of the coronary artery at the region of flow velocity measurement was calculated by quantitative angiography in two orthogonal planes.

Results: In vitro, the measured APV multiplied with the luminal area revealed a significant correlation to the given perfusion volumes in all diameters under laminar flow conditions $\left(r^{2}>0.85\right)$. Above a critical Reynolds number of 500 - indicating turbulent flow - the volume calculation derived by FW velocity measurement underestimated the actual rate of perfusion by up to $22.5 \%$ (I3 $\pm 4.6 \%)$. In vivo, the hyperemic APV was measured irrespectively of the inherent deviation towards lower velocities. In 15 of 75 patients $(20 \%)$ the maximum APV exceeded the velocity of the critical Reynolds number determined by the in vitro experiments.

Conclusion: Doppler guide wires are a valid tool for exact measurement of coronary flow velocity below a critical Reynolds number of 500 . Reaching a coronary flow velocity above the velocity of the critical Reynolds number may result in an underestimation of the CFVR caused by turbulent flow. This underestimation of the flow velocity may reach up to $22.5 \%$ compared to the actual volumetric flow. Cardiologists should consider this phenomena in at least $20 \%$ of patients when measuring CFVR for clinical decision making.
\end{abstract}




\section{Background}

Cardiologists are able to quantify the coronary flow velocity during coronary angiography by means of a Doppler guide wire system. The computer analysis of the Doppler shift reflects the actual blood flow velocity in the coronary artery [1]. In addition, measuring the coronary flow velocity reserve (CFVR) during pharmacological stimulation of coronary blood flow can characterize the vaso-dilatory capacity of the coronary arteries [2]. The CFVR is the ratio of hyperemic flow velocity divided by baseline flow velocity. It correlates with the functional severity of epicardial coronary artery stenosis $[3,4]$. The CFVR is well established for physiologically guided decision making in the catheter laboratory [5-7]. The results of interventional and of medical treatment in coronary artery disease have been assessed by intra-coronary Doppler studies [8,9]. An impaired CFVR was described after angiographically successful coronary angioplasty despite lack of residual stenosis [10]. Various patient-related factors such as coronary micro-embolization, coronary spasm, micro-thrombi or endothelial dysfunction have been discussed as possible causes for an impaired flow velocity reserve measured by Doppler wire $[11,12]$. Assuming a laminar flow profile, volumetric flow analysis by means of a Doppler-tipped wire showed a high correlation between the real flow and the measured Doppler-shift in vitro and in vivo $[13,14]$. However, direct analysis of coronary flow pattern in open heart surgery showed the occurrence of turbulent flow even in non-atherosclerotic coronary arteries [15]. Axialdirected beam studies with Doppler probes revealed a limitation of the accuracy of Doppler flow velocity measurements related to the occurrence of turbulent flow $[16,17]$. The critical Reynolds number (CRN) indicates the flow velocity, which discriminates between laminar and turbulent flow according to vessel diameter. Above a CRN of 80 - 710 the flow profile of circulating blood changes from laminar to turbulent [18]. We hypothesized that turbulent flow may also occur in human coronary arteries influencing Doppler flow measurements. To prove this hypothesis, we performed in vitro experiments to examine the influence of the flow profile on the shift of the Doppler signal. The occurrence rate of high flow velocities above the CRN assuming the presence of turbulent flow was investigated by in vivo studies.

\section{Methods}

We used 0.014 inch Doppler-tipped guide wires (FloWire $^{\mathrm{TM}}$, Cardiometrics, Carolina, USA) for the in vitro, and for the in vivo study. A piezo-electric ultrasound transducer was integrated in the tip of the $175 \mathrm{~cm}$ long wire. The signal of the $12 \mathrm{MHz}$ pulsed Doppler was analyzed by a computer system (FlowMap ${ }^{\mathrm{TM}}$, Cardiometrics) using fast Fourier transformation. Technical details of the Doppler System were described elsewhere [19].

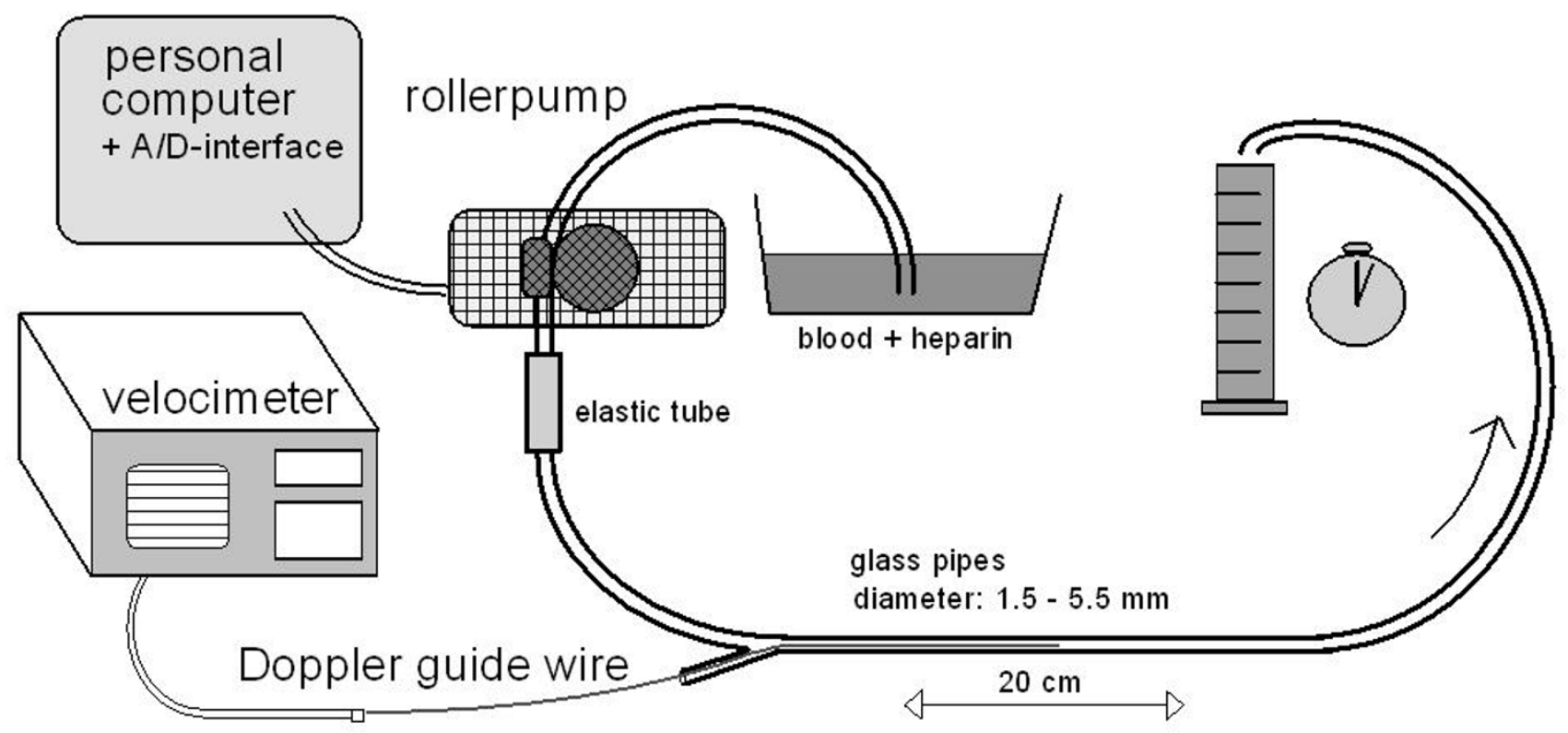

Figure I

Setup for the in vitro measurements. Heparinized blood was pumped through glass pipes of diameters of 1.5 to $5.5 \mathrm{~mm}$ at defined flow rates. 


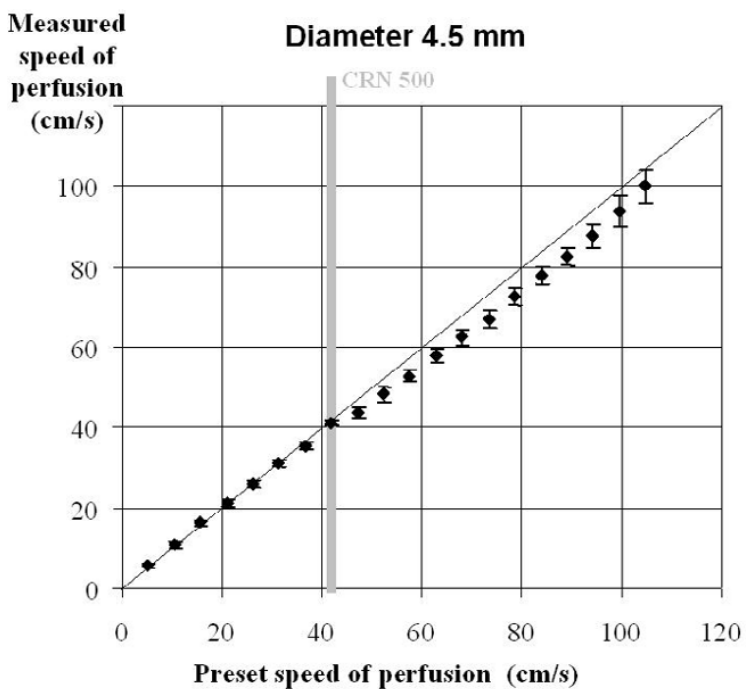

\section{Figure 2}

Mean values and standard deviations of 20 in vitro Doppler flow measurements at each per perfusion speed in glass pipes of $4.5 \mathrm{~mm}$ diameter. The flow velocity of the critical Reynolds number (CRN) 500 is marked.

\section{In vitro experiments}

We used glass pipes of a length of $20 \mathrm{~cm}$ in the in vitro model. They had defined inner diameters of 1.5, 2.5, 3.5, 4.5 , and $5.5 \mathrm{~mm}$ to simulate coronary vessel. The glass pipes were perfused by a roller pump with heparinized blood from volunteer donors. Careful attention was paid for an exact calibration of the pump flow before each measurement using volumetric calibration. Setting different pump speeds according to physiologic velocities of coronary blood flow, the mean flow velocity was varied between 5 and $180 \mathrm{~cm} / \mathrm{s}$. The motor currency of the roller pump was directly supervised by a personal computer via an analog-digital interface. Careful attention was paid to keep the motor currency stable during all flow velocity recordings. Twenty measurements were taken at each flow velocity after repositioning of the Doppler wire in the mid segment of the glass pipes. The wire was twisted and moved until a stable signal was obtained before each measurement. The mean value of the average peak velocity (APV) sampled by continuous recording over a two minute period was taken for further analysis at each perfusion speed.

\section{Measurements of coronary flow velocity in vivo Patient selection}

All patients participating in this study, were scheduled for an elective coronary angiography due to pathological findings in non-invasive stress test, and stable angina pectoris. They had given informed consent for coronary ang- iography, and for percutaneous coronary intervention (PCI) if necessary. All lesions were de novo lesions. None of the patients had undergone previous PCI of the target vessel. To have a similar blood viscosity in all patients, careful attention was paid on a normal (within the normal range) hematocrit value in all study patients before coronary angiography. All patients had also given written informed consent to participate in the study. They were well informed about intra-coronary flow velocity measurements. The study protocol was approved by the ethical committee of our University. Aortic stenosis, arterial hypertension ( $2^{\text {nd }}$ degree or above), and other co-morbidities influencing the blood viscosity (e.g. leukemia) were exclusion criteria.

\section{Angiography protocol}

Coronary angiography was performed in Judkin's technique by a femoral approach through a $7 \mathrm{~F}$ sheath. A standard guiding catheter was placed with its tip in the coronary ostium of the target vessel. The 0.014 " Doppler guide wire was placed $1-2 \mathrm{~cm}$ distal to the stenosis after intravenous administration of 10.000 IU of heparin.

After intra-coronary injection of $0.2 \mathrm{mg}$ nitroglycerin quantitative coronary angiography (QCA) of the target lesion was obtained. The QCA was performed in two orthogonal projections by Philips DCI automated coronary analysis using the $7 \mathrm{~F}$ guiding catheter as reference standard [20]. Lesion severity was determined as percentage diameter stenosis relative to the angiographically normal diameter. Mean values of the vessel diameter 3 to 5 $\mathrm{mm}$ distal to the tip of the Doppler wire of the two planes were taken for further analysis.

An adenosine bolus was injected through the guiding catheter to induce maximum hyperemic blood flow after registration of the APV at rest. We used $12 \mu \mathrm{g}$ adenosine for the right, and $18 \mu \mathrm{g}$ adenosine for the left coronary artery. The CFVR was computed as the ratio of hyperemic to basal average peak velocity (APV). A PCI was performed in those patients with an impaired CFVR below 2.0. Balloon inflations were repeated or a stent was implanted until an angiographically satisfying result was achieved in all patients. The maximum values of the APV were taken from each patient for further analysis.

\section{Calculations and statistical analysis}

The Reynolds number ( $\mathrm{Re}$ ) can be calculated from the mean luminal diameter (MLD) multiplied with the flow velocity (APV/2) and the density (Q) divided by the viscosity of blood (n):

$\mathrm{Re}=\frac{\mathrm{MLD}^{*} \mathrm{APV} / 2 * \mathrm{Q}}{\mathrm{n}}$ 


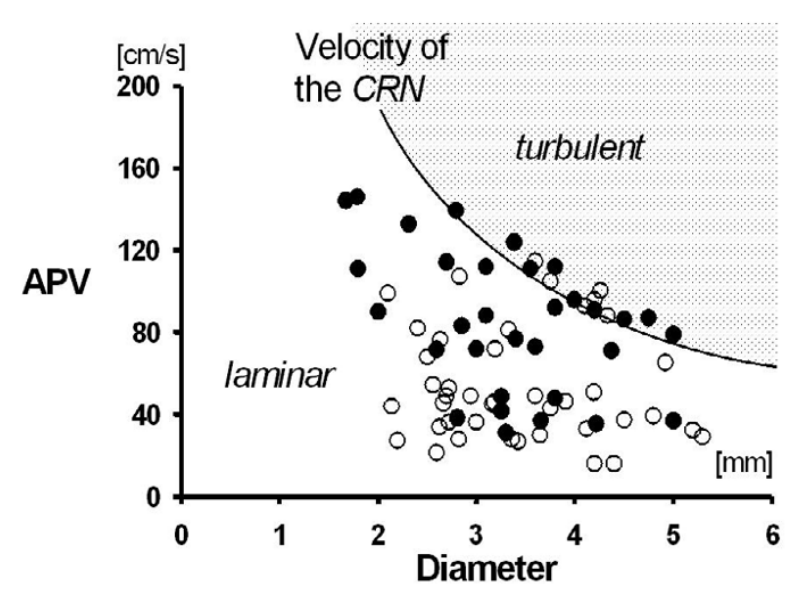

Figure 3

Maximum value of the average peak velocity APV in 43 patients before $(\bigcirc)$ or after an angiographically successful angioplasty of 32 patients (O). The highest values of APV were taken for each individual. The flow velocity at the critical Reynolds number (CRN) 500 describes the change from laminar to turbulent flow profile.

$\mathrm{MLD}=$ mean luminal diameter, $\mathrm{APV} / 2=$ mean of average peak velocity, $\mathrm{Q}=$ density of blood $\left(1,060 \mathrm{~kg}^{*} \mathrm{~m}^{-3}\right), \mathrm{n}=$ viscosity of blood $\left(4^{*} 10^{-3} \mathrm{~Pa}^{*} \mathrm{~s}\right)$.

The laminar flow profile of blood changes to a turbulent flow above the CRN. The flow velocity of the CRN was calculated using the MLD which was obtained by QCA in all patients. Blood flow rate (BF) was calculated from the APV divided by 2 and the luminal area (LA) of the vessel $\left(\pi^{*}(\mathrm{MLD} / 2)^{2}\right)[21]$ :

$\mathrm{BF}=\mathrm{LA} * \mathrm{APV} / 2=\mathrm{APV} / 2 * \pi *(\mathrm{MLD} / 2)^{2}$

$\mathrm{BF}=$ blood flow, $\mathrm{LA}=$ luminal area $\left(\pi^{*}\right.$ vessel radius $\left.{ }^{2}\right)$; $\mathrm{APV} / 2=$ mean of average peak velocity, $\mathrm{MLD}=$ mean luminal diameter.

The correlation coefficient $(\mathrm{r})$ and its square value $\left(\mathrm{r}^{2}\right)$ were obtained by computerized calculation with Excel 2000 (Microsoft Corp.). All values are expressed as mean \pm standard deviation.

\section{Results}

\section{In vitro studies}

The BF measured by Doppler showed excellent correlations to the given perfusion speeds in all diameters under laminar flow conditions: we calculated an $\mathrm{r}^{2}-$ value of 0.854 in the $1.5 \mathrm{~mm}$ system, in the $2.5 \mathrm{~mm}$ glass pipes $\mathrm{r}^{2}$ was 0.957 , in the $3.5 \mathrm{~mm}$ diameter we found an $\mathrm{r}^{2}$ of 0.968 , in the $4.5 \mathrm{~mm}$ system it was 0.989 , and in the 5.5 mm tubes we obtained an $\mathrm{r}^{2}-$ value of 0.991 respectively. The difference between the actual volume flow and the flow volume calculated from the Doppler signal was below $\pm 4.2 \%$ in all measurements under laminar perfusion (Table 1). According to our measurements, we calculated a critical Reynolds (CRN) number of about 500 $(493$ - 509). At flow velocities above the CRN (= turbulent flow) the velocity measured by the Doppler wire was up to $12.8 \%$ lower in $1.5 \mathrm{~mm}$ glass pipes, up to $22.5 \%$ lower in $2.5 \mathrm{~mm}$ glass pipes, up to $14.7 \%$ lower in 3.5 $\mathrm{mm}$ glass pipes, up to $8.9 \%$ lower in $4.5 \mathrm{~mm}$ glass pipes, and up to $13.1 \%$ lower in $5.5 \mathrm{~mm}$ glass pipes compared to the quantitatively measured perfusion volumes. The average underestimation of blood flow under turbulent conditions was $13 \pm 4.6 \%$ varying between $1.8 \%$ and $22.5 \%$.

\section{In vivo measurements}

It was the aim of our study to transfer the in vitro findings to the clinical routine of intra-coronary flow velocity measurements in diseased coronary arteries of patients in the catheter laboratory. It was unclear whether these critical flow velocities could occur in a relevant number of patients. However, these measurements were performed irrespectively of the inherent deviation caused by the described phenomena.

A total of 75 patients $(58$ men $=77.3 \%)$ were studied with an average age of $59.5 \pm 11.2$ years. The baseline characteristics, and the results of the flow velocity measurements of the study patients are summarized in Table 2.

The flow velocity was measured in 23 patients (31\%) in the right coronary artery (RCA), in 18 patients (35\%) in the circumflex artery, and in 34 patients (65\%) in the left anterior descending artery. A PCI was necessary in 42 patients $(56 \%)$. In these patients the CFVR increased from $1.6 \pm 0.40$ to $2.7 \pm 0.35$ after PCI. Only 12 patients received a stent due to an angiographically unsatisfying result of the balloon inflation. We measured the maximum hyperemic APV value in 43 patients before, and in 32 patients after an angioplasty. Among those 43 patients were 33 patients $(77 \%)$ in whom the angioplasty was deferred due to an initially recorded CFVR above 2.0. Peak APV values were measured in 32 patients (76\%) post angioplasty. In 10 patients (24\%) the recording of the APV reached its maximum before the intervention. However, the highest individual APV value of each patient was used for further analysis. Figure 3 summarizes the maximum values of the hyperemic APV of all patients.

Peak values of APV varied between $14 \mathrm{~cm} / \mathrm{s}$ and $154 \mathrm{~cm} /$ s. In 15 patients $(20 \%)$ the maximum APV exceeded the velocity of the CRN. In 7 patients $(9.3 \%)$ the maximum APV in the RCA, and in 8 patients $(10.7 \%)$ the maximum 


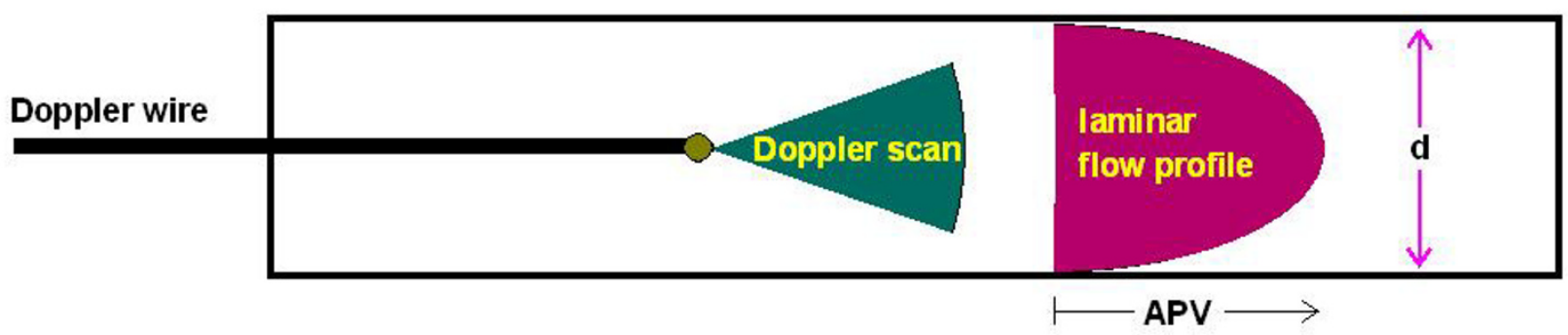

\section{laminar flow $=($ APV $/ 2) *(d / 2)^{2} * \pi$}

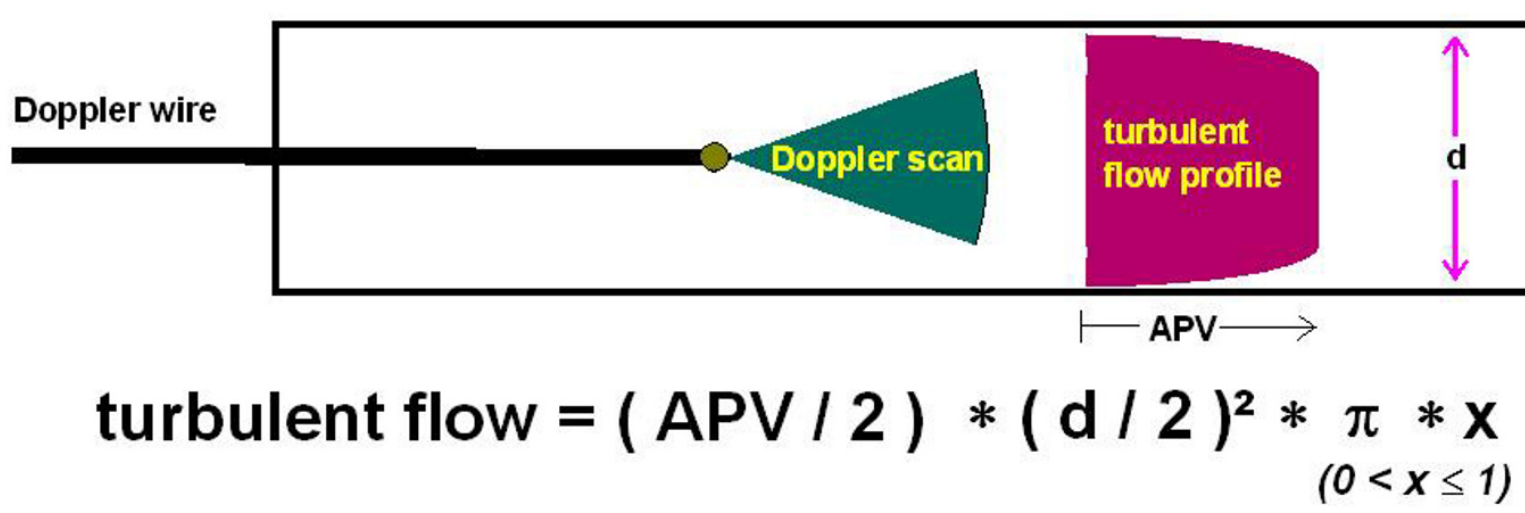

\section{Figure 4}

Flow profile under laminar and turbulent conditions: Under laminar flow the average peak velocity divided by 2 (APV/2) multiplied with the lamina area (vessel diameter $=\mathrm{d}$ ) can be used for exact quantitative measurement of the blood flow. Under turbulent flow an underestimation of the blood flow occurs when measured with a Doppler wire.

APV in the left coronary artery exceeded the velocity of the $\mathrm{CRN}$. The average maximum values of the APV were $79 \pm$ $17.2 \mathrm{~cm} / \mathrm{s}$ after PCI $(\mathrm{n}=32)$, and $61 \pm 14.7 \mathrm{~cm} / \mathrm{s}$ before angioplasty $(\mathrm{n}=43)$.

\section{Discussion}

We proved the hypothesis that the occurrence of turbulent flow influences the accuracy of Doppler flow velocity measurements by a combined in vitro and in vivo study. About $20 \%$ of patients have coronary flow velocities above the critical Reynolds number during pharmacologically induced hyperemia. We therefore assume that a turbulent flow profile can occur under in vivo conditions resulting in an underestimation of the coronary blood flow.

\section{In vitro measurements}

We were able to demonstrate an excellent correlation between perfusion volume and the calculated volume derived from Doppler flow velocity measurement under in vitro conditions at low flow velocities as previously described by other research groups [22]. At flow velocities above the CRN of about 500, flow volume calculations based on the shift of the Doppler signal showed a tendency to underestimate the blood flow as illustrated by Figure 4. This phenomena can be explained by our hypothesis that the Doppler wire measured the true peak value of APV under turbulent conditions, since the intraluminal peak APV is diminished under turbulent flow conditions. It does not reach the same value which would have been recorded with equal perfusion volumes under laminar flow conditions. 
Table I: Mean values \pm standard deviation of 20 in vitro Doppler flow measurements of the average peak velocity at each perfusion speed in glass pipes of I.5 - 5.5 mm. The perfusion speed was adjusted up to $700 \mathrm{ml} / \mathrm{min}(2.5-5.5 \mathrm{~mm}$ diameter) and up to $200 \mathrm{ml} / \mathrm{min}$ in pipes of $1.5 \mathrm{~mm}$ diameter. The flow velocity was calculated of the blood flow (Perf.) and the luminal area of the pipe. The velocity value at the critical Reynolds number $(\Longrightarrow)$ is marked for each diameter.

\begin{tabular}{|c|c|c|c|c|c|c|c|c|c|c|c|c|c|c|c|}
\hline \multirow{3}{*}{$\begin{array}{l}\text { Diameter: } \\
\text { Velocity of CRN } \\
\text { Perf. }(\mathrm{ml} / \mathrm{min})\end{array}$} & \multicolumn{3}{|c|}{$1.5 \mathrm{~mm}$} & \multicolumn{3}{|c|}{$2.5 \mathrm{~mm}$} & \multicolumn{3}{|c|}{$3.5 \mathrm{~mm}$} & \multicolumn{3}{|c|}{$4.5 \mathrm{~mm}$} & \multicolumn{3}{|c|}{$5.5 \mathrm{~mm}$} \\
\hline & \multicolumn{3}{|c|}{$125.8 \mathrm{~cm} / \mathrm{s}$} & \multicolumn{3}{|c|}{$75.5 \mathrm{~cm} / \mathrm{s}$} & \multicolumn{3}{|c|}{$53.9 \mathrm{~cm} / \mathrm{s}$} & \multicolumn{3}{|c|}{$41.9 \mathrm{~cm} / \mathrm{s}$} & \multicolumn{3}{|c|}{$34.3 \mathrm{~cm} / \mathrm{s}$} \\
\hline & Velocity $(\mathrm{cm} / \mathrm{s})$ & APV & & Velocity $(\mathrm{cm} / \mathrm{s})$ & APV & & Velocity $(\mathrm{cm} / \mathrm{s})$ & APV & & Velocity $(\mathrm{cm} / \mathrm{s})$ & APV & & Velocity $(\mathrm{cm} / \mathrm{s})$ & APV & \\
\hline & & Mean & $\pm S D$ & & Mean & $\pm \mathrm{SD}$ & & Mean & $\pm \mathrm{SD}$ & & Mean & $\pm \mathrm{SD}$ & & Mean & $\pm \mathrm{SD}$ \\
\hline 50 & 47.2 & 94.7 & \pm 1.23 & 17.0 & 35.7 & \pm 0.65 & 8.7 & 17.4 & \pm 0.48 & 5.2 & 11.4 & \pm 0.48 & 3.5 & 7.1 & \pm 0.08 \\
\hline 100 & 94.3 & 183.7 & \pm 1.56 & 34.0 & 68.0 & \pm 0.63 & 17.3 & 34.1 & \pm 0.97 & 10.5 & 21.6 & \pm 0.73 & 7.0 & 14.0 & \pm 0.0 \\
\hline 150 & 141.5 & 259.6 & \pm 3.88 & 50.9 & 97.0 & \pm 1.52 & 26.0 & 51.6 & \pm 0.73 & 15.7 & 32.6 & \pm 0.66 & 10.5 & 20.7 & \pm 0.57 \\
\hline 200 & 188.6 & 328.9 & \pm 7.56 & 67.9 & 120.5 & \pm 2.38 & 34.7 & 67.1 & \pm 0.67 & 21.0 & 42.3 & \pm 0.71 & 14.0 & 27.2 & \pm 0.51 \\
\hline 250 & & & & 84.9 & 145.2 & \pm 3.79 & 43.3 & 82.1 & \pm 0.77 & 26.2 & 51.7 & \pm 0.78 & 17.5 & 33.5 & \pm 0.87 \\
\hline 300 & & & & 101.9 & 169.6 & \pm 5.28 & 52.0 & 96.5 & \pm 0.97 & 31.4 & 62.3 & \pm 0.78 & 21.1 & 39.1 & \pm 1.56 \\
\hline 350 & & & & 118.8 & 195.3 & \pm 6.91 & 60.6 & 110.5 & \pm 0.80 & 36.7 & 70.9 & \pm 0.73 & 24.6 & 44.5 & \pm 2.36 \\
\hline 400 & & & & 135.8 & 220.8 & \pm 8.29 & 69.3 & 124.3 & \pm 1.61 & 41.9 & 82.3 & \pm 0.71 & 28.1 & 50.8 & \pm 2.58 \\
\hline 450 & & & & 152.8 & 246.7 & \pm 11.04 & 78.0 & 140.7 & \pm 0.90 & 47.2 & 87.1 & \pm 1.34 & 31.6 & 55.6 & $\pm 3.4 \mathrm{I}$ \\
\hline 500 & & & & 169.8 & 271.1 & \pm 12.50 & 86.6 & 152.1 & $\pm|.5|$ & 52.4 & 96.4 & \pm 1.96 & 35.1 & 61.9 & \pm 2.74 \\
\hline 550 & & & & 186.7 & 296.5 & \pm 14.73 & 95.3 & 163.6 & \pm 1.62 & 57.6 & 105.5 & \pm 1.57 & 38.6 & 67.1 & \pm 3.63 \\
\hline 600 & & & & 203.7 & 340.6 & \pm 14.79 & 103.9 & 178.8 & \pm 2.32 & 62.9 & 115.6 & \pm 1.83 & 42.1 & 73.4 & \pm 3.98 \\
\hline 650 & & & & 220.7 & 362.6 & \pm 15.40 & 112.6 & 192.7 & \pm 1.56 & 68.1 & 124.8 & \pm 1.96 & 45.6 & 79.5 & \pm 4.10 \\
\hline 700 & & & & 237.7 & 368.3 & \pm 25.65 & 121.3 & 206.9 & \pm 2.08 & 73.4 & 133.8 & \pm 2.32 & 49.1 & 85.8 & \pm 4.91 \\
\hline
\end{tabular}


Table 2: Data of 75 patients undergoing elective coronary angiography: The degree of stenosis was calculated by quantitative angiography in two orthogonal planes. Mean values \pm standard deviations (SD), APV: highest value of the average peak velocity (under baseline conditions and maximal hyperemia), the coronary flow velocity reserve was measured before angioplasty (CFVR before PCI) in 75 patients, and after angioplasty (CFVR post $\mathrm{PCl})$ in 42 patients.

\begin{tabular}{llll}
\hline & & Mean & \pm SD \\
\hline Age & $($ years $)$ & 59.5 & \pm 11.2 \\
Degree of stenosis $_{\text {APV }_{\text {base }}}(\%)$ & 61.7 & \pm 9.2 \\
APV $_{\text {max }}$ & $(\mathrm{cm} / \mathrm{s})$ & 34.2 & \pm 17.87 \\
CFVR $_{\text {before PCI }}$ & $(\mathrm{cm} / \mathrm{s})$ & 67.3 & \pm 33.65 \\
CFVR $_{\text {post PCl }}$ & $(\mathrm{n}=75)$ & 2.0 & \pm 0.71 \\
\hline
\end{tabular}

The amount of the mean underestimation of the flow velocity measured by Doppler wire was $13.1 \%$ under relatively high perfusion speeds above the CRN. The inaccuracy of the Doppler wire was $4.2 \%$ under laminar flow. These results qualify the Doppler wire as a valid, and highly exact tool for quantitative coronary blood flow measurements under low flow velocities associated with a laminar flow profile. The CRN is reciprocally dependent on the vessel diameter given by the MLD. The velocity at the value of the CRN exceeds the normal physiological range in vessels with an MLD below $2 \mathrm{~mm}$. Thus, we would suggest to place the Doppler wire in a distal nonbranching segment of the coronary artery to achieve the highest accuracy of the flow velocity measurement. On the other side, the accuracy of measuring the MLD by QCA is limited in smaller and more calcified vessels [23].

\section{In vivo measurements}

According to an inaccuracy of only $\pm 4.2 \%$ under laminar flow conditions we regard intra-coronary Doppler wires as a valid tool for quantification of coronary blood flow at rest. However, several studies investigated hyperemic blood flow after pharmacological stimulation by papaverine or adenosine. Under resting conditions, we did not observe flow velocities which were above the velocity at values of the CRN. But under hyperemic conditions, about $20 \%$ of patients reached flow velocities above the velocity of the CRN after injection of adenosine. Based on our in vitro observations, we assume that the Doppler shift derived flow velocity underestimates the coronary peak blood flow in one fifth of patients by about $13 \%$.

Measurements of CFVR can be relevantly influenced by a maximum APV above the CRN. For example, the measured CFVR would be 2.3 instead of 2.6 due to the occurrence of turbulent flow during hyperemia after an angiographically successful PCI. According to the results of the DEBATE II Study, the responsible cardiologist would expect a higher restenosis rate in this patient, considering the implantation of a stent [24]. The APV values at rest were below the velocity of the CRN in all patients.
Thus, an overestimation of the CFVR related to an underestimated baseline APV does not appear very likely to happen under regular flow conditions.

Novel technologies like the so-called fractional flow reserve (FFR), or intra-coronary thermo-dilution can quantify high coronary blood flow with predominantly turbulent character independently of the present flow profile $[25,26]$. One may speculate, that changes of coronary flow profile from laminar to turbulent might have been one reason for previously reported discordance between CFVR and FFR [27]. Since turbulent flow occurs when reaching relatively high flow velocities, and healthy subjects without coronary artery disease show higher flow velocities in pharmacological tests compared to patients suffering from coronary artery disease, we assume that turbulent flow may be observed more often in healthy vessels [28]. However, measuring CFVR in diseased vessels results in relatively low peak flow velocities, therefore the chance of turbulent flow interfering with the Doppler measurements may be of less importance.

The in vitro evaluation of the CRN was performed using smooth glass pipes. In contrast to the ideal situation inside glass pipes we assume an even lower CRN in vivo when measuring APV in calcified coronary vessels. Therefore, an underestimation of flow velocity recordings might happen more often in patients than suggested by our in vitro experiments. However, we do not expect a CRN much below 500 which could also influence the accuracy of intra-coronary Doppler flow measurements at rest [29].

The velocity of the CRN depends on the vessel diameter. Saphenous vein bypass grafts show higher diameters compared to native coronary arteries which can reach MLD values of up to $8 \mathrm{~mm}$. Relevant variations of the velocity distribution in vein bypass graft were uncovered by laser Doppler anemometry [30]. Thus, the flow velocity of the CRN may be reached more often in vein grafts than in native coronary vessels. Flow velocity measurements in a 
bifurcation of a coronary artery may also influence the quality of the flow profile [31].

Recently, coronary flow reserve was also analyzed in transthoracic Doppler studies [32]. Further studies should evaluate the influence of turbulent flow on flow velocity measurements with transthoracic Doppler.

\section{Limitations of the study}

We were able to demonstrate an effect of high flow velocities on the validity of blood flow measurements with Doppler wires in smooth glass pipes. In contrast to coronary arteries these pipes did not have any elastic component, nor bending, calcification of the wall, local dissections, previously implanted stents, intramural thrombus, side branches, or changes in vessel diameter which all have an influence on the flow profile possibly causing turbulent flow $[33,34]$.

Especially the elastic component, changes in diameter, and the hematocrit influencing the viscosity of the blood might have a major influence on the CRN in human coronary arteries $[35,36]$. The derived blood flow was underestimated only at high flow velocities under in vitro conditions. In a study population of 75 patients, $20 \%$ achieved such high flow velocities above the CRN during maximal hyperemia. Today, higher doses of adenosine are given i. c. for induction of hyperemia [37]. Therefore, the proportion of patients achieving coronary peak flow velocities above the value at the CRN may be even higher due to this more intensive pharmacological stimulation. As mentioned above, in comparison to smooth and straight glass pipes, turbulent flow might occur more often in coronary arteries which show an increasing proportion of previously implanted stents. On the other hand, the elastic vessel wall can reduce the amount of turbulent flow. However, we see limitation of transferring the results of the in vitro measurements directly to the in vivo Doppler studies.

\section{Conclusion}

Below the critical Reynolds number Doppler guide wires are a highly exact and valid tool for quantitative measurements of coronary blood flow velocity. If the flow velocity exceeds the critical Reynolds number of 500, Doppler flow velocity measurements underestimate the actual flow by $13 \%$. An overestimation of the flow does not appear possible based on this phenomena. Turbulent flow occurs after pharmacological stimulation of the coronary flow blood in at least $20 \%$ of patients which could lead to an underestimation of the Doppler velocity shift derived coronary flow velocity reserve. This phenomena of turbulent flow influencing the accuracy of flow velocity measurements should therefore be taken into consideration in all studies analyzing Doppler derived coronary blood flow during hyperemia.

\section{Competing interests}

The author(s) declare that they have no competing interests.

\section{Authors' contributions}

$M F, P B$, and BMR performed the in vitro studies. MF, GSW, and HRF performed the in vivo studies. All authors provided major scientific input into the study, and reviewed the manuscript. HRF was the scientific supervisor of the project. MF, GSW, and BMR were responsible for the design of the study, and carried out all statistical analyses. MF is the corresponding author. All authors read and approved the final version of the manuscript.

\section{References}

I. Doucette JW, Corl PD, Payne HM, Flynn AE, Goto M, Nassi M, Segal $\mathrm{J}$ : Validation of a Doppler guide wire for intravascular measurement of coronary artery flow velocity. Circulation 1992, 85:|899-19|I.

2. Marcus M, Wright C, Doty D, Eastham C, Laughlin D, Krumm P, Fastenow C, Brody M: Measurements of coronary velocity and reactive hyperemia in the coronary circulation of humans. Circ Res 1981, 49:877-891.

3. Gould KL, Lipscomb K: Effects of coronary stenoses on coronary flow reserve and resistance. Am J Cardiol 1974, 34:48-55.

4. Wilson RF, Laughlin DE, Ackell PH, Chilian WM, Holida MD, Hartley C], Armstrong ML, Marcus ML, White CW: Transluminal, subselective measurement of coronary artery blood flow velocity and vasodilator reserve in man. Circulation 1985, 72:82-92.

5. Ferrari M, Schnell B, Werner GS, Figulla HR: Safety of deferring angioplasty in patients with normal coronary flow velocity reserve. J Am Coll Cardiol 1999, 33:82-87.

6. Kern MJ, Dupouy P, Drury JH, Aguirre FV, Aptecar E, Bach RG, Caracciolo EA, Donohue TJ, Rande JL, Geschwind HJ, et al:: Role of coronary artery lumen enlargement in improving coronary blood flow after balloon angioplasty and stenting: a combined intravascular ultrasound Doppler flow and imaging study. J Am Coll Cardiol 1997, 29: I 520-I527.

7. White CW, Wright CB, Doty DB, Hiratza LF, Eastham CL, Harrison DG, Marcus ML: Does visual interpretation of the coronary arteriogram predict the physiologic importance of a coronary stenosis? N Engl J Med 1984, 310:819-824.

8. Serruys PW, di Mario C, Piek J, Schroeder E, Vrints C, Probst P, de Bruyne B, Hanet C, Fleck E, Haude M, et al.: Prognostic value of intracoronary flow velocity and diameter stenosis in assessing the short- and long-term outcomes of coronary balloon angioplasty: the DEBATE Study (Doppler Endpoints Balloon Angioplasty Trial Europe). Circulation 1997, 96:3369-3377.

9. Duffy SJ, Castle SF, Harper RW, Meredith IT: Contribution of vasodilator prostanoids and nitric oxide to resting flow, metabolic vasodilation, and flow-mediated dilation in human coronary circulation. Circulation 1999, 100:1951-1957.

10. Ge J, Erbel R, Zamorano J, Haude M, Kearney P, Gorge G, Meyer J: Improvement of coronary morphology and blood flow after stenting. Assessment by intravascular ultrasound and intracoronary Doppler. Int J Card Imaging 1995, I I:8I-87.

11. McGinn AL, White CW, Wilson RF: Interstudy variability of coronary flow reserve. Influence of heart rate, arterial pressure, and ventricular preload. Circulation 1990, 81:1319-1330.

12. Serruys PW, Zijlstra F, Laarman GJ, Reiber HH, Beatt K, Roelandt J: A comparison of two methods to measure coronary flow reserve in the setting of coronary angioplasty: intracoronary blood flow velocity measurements with a Doppler catheter, and digital subtraction cineangiography. Eur Heart J 1989, 10:725-736.

13. Labovitz AJ, Anthonis DM, Cravens TL, Kern MJ: Validation of volumetric flow measurements by means of a Doppler-tipped 
coronary angioplasty guide wire. Am Heart J 1993 , I 26:|456-|46|.

14. Ferrari M, Andreas S, Werner GS, Wicke J, Kreuzer H, Figulla HR: Evaluation of an active coronary perfusion balloon device using Doppler flow wire during PTCA. Cathet Cardiovasc Diagn 1997, 42:84-89.

15. Kajiya F, Matsuoka S, Ogasawara Y, Hiramatsu O, Kanazawa S, Wada Y, Tadaoka S, Tsujioka K, Fujiwara T, Zamir M: Velocity profiles and phasic flow patterns in the non-stenotic human left anterior descending coronary artery during cardiac surgery. Cardiovasc Res 1993, 27:845-850.

16. Levine RA, Jimoh A, Cape EG, McMillan S, Yoganathan AP, Weyman $A E$ : Pressure recovery distal to a stenosis: potential cause of gradient "overestimation" by Doppler echocardiography. J Am Coll Cardiol 1989, I3:706-7I5.

17. Denardo SJ, Yock PG, Hargrave VK, Srebro JP, Ports TA, Talbot L: Differentiation of abnormal blood flow patterns in coronary arteries based on Doppler catheter recordings. Angiology 1991, 42:7||-725.

18. Cho YI, Back LH, Crawford DW: Effect of simulated hyperemia on the flow field in a mildly atherosclerotic coronary artery casting of man. Aviat Space Environ Med 1985, 56:2 I2-219.

19. Ofili EO, Kern MJ, Labovitz AJ, St Vrain JA, Segal J, Aguirre FV, Castello R: Analysis of coronary blood flow velocity dynamics in angiographically normal and stenosed arteries before and after endolumen enlargement by angioplasty. J Am Coll Cardiol 1993, 21:308-316.

20. Reiber JH, van der Zwet PM, Koning G, von Land CD, van Meurs B, Gerbrands J], Buis B, van Voorthuisen AE: Accuracy and precision of quantitative digital coronary arteriography: observer-, short-, and medium-term variabilities. Cathet Cardiovasc Diagn 1993, 28: 187-198.

21. Ferrari M, Werner GS, von zur Muhlen F, Andreas S, Wicke J, Figulla HR: Coronary flow analysis during autoperfusion angioplasty. Coronary Artery Disease 1997, 8:697-702.

22. Cole JS, Hartley CJ: The pulsed Doppler coronary artery catheter preliminary report of a new technique for measuring rapid changes in coronary artery flow velocity in man. Circulation 1977, 56: 18-25.

23. Yamagishi M, Hosokawa H, Saito S, Kanemitsu S, Chino M, Koyanagi $\mathrm{S}$, Urasawa K, Ito K, Yo S, Honye J, et al.: Coronary disease morphology and distribution determined by quantitative angiography and intravascular ultrasound - re-evaluation in a cooperative multicenter intravascular ultrasound study (COMIUS). Circ J 2002, 66:735-740.

24. Serruys PW, de Bruyne B, Carlier S, Sousa JE, Piek J, Muramatsu T, Vrints C, Probst P, Seabra-Gomes R, Simpson I, et al.: Randomized comparison of primary stenting and provisional balloon angioplasty guided by flow velocity measurement. Doppler Endpoints Balloon Angioplasty Trial Europe (DEBATE) II Study Group. Circulation 2000, 102:2930-2937.

25. Fearon WF, Farouque HM, Balsam LB, Caffarelli AD, Cooke DT, Robbins RC, Fitzgerald PJ, Yeung AC, Yock PG: Comparison of coronary thermodilution and Doppler velocity for assessing coronary flow reserve. Circulation 2003, 108:2198-2200.

26. Tron C, Donohue T], Bach RG, Aguirre FV, Caracciolo EA, Wolford TL, Miller DD, Kern MJ: Comparison of pressure-derived fractional flow reserve with poststenotic coronary flow velocity reserve for prediction of stress myocardial perfusion imaging results. Am Heart J 1995, 130:723-733.

27. Meuwissen M, Siebes M, Chamuleau SA, van Eck-Smit BL, Koch KT, de Winter RJ, Tijssen JG, Spaan JA, Piek JJ: Hyperemic stenosis resistance index for evaluation of functional coronary lesion severity. Circulation 2002, 106:44I-446.

28. Kern MJ, Bach RG, Mechem CJ, Caracciolo EA, Aguirre FV, Miller LW, Donohue TJ: Variations in normal coronary vasodilatory reserve stratified by artery, gender, heart transplantation and coronary artery disease. J Am Coll Cardiol 1996, 28: II54-II60.

29. Pincombe B, Mazumdar JN: A mathematical study of blood flow through viscoelastic walled stenosed arteries. Australas Phys Eng Sci Med 1995, 18:8I-88.

30. Einav S, Avidor J, Vidne B: Haemodynamics of coronary arterysaphenous vein bypass. Journal of Biomedical Engineering 1985, 7:305-309.
31. Peacock J, Jones T, Tock C, Lutz R: An in vitro study on the effect of branch points on the stability of coronary artery flow. Med Eng Phys 1997, 19:101-108.

32. Tani T, Tanabe K, Tani M, Ono F, Katayama M, Tamita K, Kaji S, Yamamuro A, Nagai K, Shiratori K, et al:: Quantitative assessment of harmonic power doppler myocardial perfusion imaging with intravenous Levovist in patients with myocardial infarction: comparison with myocardial viability evaluated by coronary flow reserve and coronary flow pattern of infarctrelated artery. Cardiovasc Ultrasound 2005, 3:22.

33. Bertram CD: The dynamics of collapsible tubes. Symposia of the Society for Experimental Biology 1995, 49:253-264.

34. Bluestein D, Niu L, Schoephoerster RT, Dewanjee MK: Fluid mechanics of arterial stenosis: relationship to the development of mural thrombus. Ann Biomed Eng 1997, 25:344-356.

35. Jones SA: A relationship between Reynolds stresses and viscous dissipation: implications to red cell damage. Ann Biomed Eng 1995, 23:21-28.

36. Bascom PA, Johnston KW, Cobbold RS, Ojha M: Relation of the flow field distal to a moderate stenosis to the Doppler power. Ultrasound Med Biol 1997, 23:25-39.

37. Aymong ED, Curtis MJ, Youssef M, Graham MM, Shewchuk L, Leschuk W, Anderson T]: Abciximab attenuates coronary microvascular endothelial dysfunction after coronary stenting. Circulation 2002, 105:2981-2985.

Publish with Bio Med Central and every scientist can read your work free of charge

"BioMed Central will be the most significant development for disseminating the results of biomedical research in our lifetime. "

Sir Paul Nurse, Cancer Research UK

Your research papers will be:

- available free of charge to the entire biomedical community

- peer reviewed and published immediately upon acceptance

- cited in PubMed and archived on PubMed Central

- yours - you keep the copyright 